\title{
Musical pluralism and the science of music
}

\author{
Anton Killin \& Adrian Currie \\ Penultimate version, forthcoming in the European Journal for \\ Philosophy of Science
}

\section{Abstract:}

The scientific investigation of music requires contributions from a diverse array of disciplines (e.g. anthropology, musicology, neuroscience, psychology, music theory, music therapy, sociology, computer science, evolutionary biology, archaeology, acoustics and philosophy). Given the diverse methodologies, interests and research targets of the disciplines involved, we argue that there is a plurality of legitimate research questions about music, necessitating a focus on integration. In light of this we recommend a pluralistic conception of music-that there is no unitary definition divorced from some discipline, research question or context. This has important implications for how the scientific study of music ought to proceed: we show that some definitions are complementary, that is, they reflect different research interests and ought to be retained and, where possible, integrated, while others are antagonistic, they represent real empirical disagreement about music's nature and how to account for it. We illustrate this in discussion of two related issues: questions about the evolutionary function (if any) of music, and questions of the innateness (or otherwise) of music. These debates have been, in light of pluralism, misconceived. We suggest that, in both cases, scientists ought to proceed by constructing integrated models which take into account the dynamic interaction between different aspects of music.

Keywords: Definitions of music; musicality; pluralism; musical cognition; evolution of music.

\section{Introduction}

Music is a complex and fascinating target of scientific inquiry. Nevertheless, theorists disagree on what music is-on how best to characterise or define it (see e.g. Davies, 2012a; McKeown-Green, 2014). We argue that although some of this disagreement should be retained, some should be resolved. That is, contra several 
attempts to provide a unitary definition of music (e.g. Kania, 2011; Levinson, 1990;

Godt, 2005), we advocate a form of conceptual pluralism - that is, there is no objective, definitive definition of music independent of some explanatory context; rather, there are multiple, non-equivalent, legitimate concepts of music. Our argument is based on an examination of musical science itself: it is plausible, given the range of questions and evidence which scientific investigation of music requires, that there is no unitary definition of music simpliciter.

Moreover, we argue that musical pluralism has positive consequences: it can lead and drive integration in the study of music. To this end, we distinguish complementary and antagonistic relationships between definitions. Complementary definitions target different aspects of music, or music in different contexts, while antagonistic definitions give rise to empirical disagreements. Embracing a plurality of concepts does not entail accepting every one. Indeed, definitions and empirical work are not independent. Given a particular research question, some definitions can be more or less appropriate, and determining the best one for the job can itself be an empirical task. In other words, good definitions are not necessarily stipulated assumptions: they can be legitimate research findings. Indeed, to render some aspect of a real-world phenomenon amenable to scientific investigation, scientists often need to approach definitions somewhat instrumentally: operational definitions are called for. ${ }^{1}$ The relationship between

$1 \quad$ An anonymous referee points out that such operational, instrumental definitions often require a stipulated, general account of 'music' to get off the ground, otherwise the relationship between some of the concepts we discuss, for instance the distinction between 'music' and 'musicality', is decidedly ambiguous. This might be right, the relationship between the various concepts required to make music scientifically tractable can be very complex. We take this to be grist for our mill: on our view, different research agendas require a number of different, but importantly related concepts. Considering how these concepts interact is an important part of integrating such perspectives. 
evaluative and instrumental definitions is complex, and we think the framework we present in $§ 2$ gives some guidance for navigating this.

We proceed as follows. In the next section we provide a rough and partial sketch of the complexity of musical investigation. In $\S 3$ we draw on this to argue for pluralism. In the remainder of the paper, we illustrate our point and tie discussion to scientific practice. In $\S 4$ we discuss the relationship between music and evolution and in $\S 5$ we turn to music's innateness (or otherwise).

\section{The Science of Music: A Sketch}

This section sketches the science of music along two lines. We discuss the research agendas which guide inquiry $(\S 2.1)$ and the lines of evidence $(\S 2.2)$ which are drawn upon. This picture forms the basis of our argument for pluralism in $\S 3$. It is important to note that the view we present here is both schematic and heuristic. Particularly in terms of research agendas, our account is inadequate as an attempt to capture the actual landscape of music research. However, in regards to our argument about musical pluralism, this is a feature rather than a bug. Our aim is to show how complex and multi-faceted musical research is, and this is used to motivate pluralism in $\S 3$. That the sketch fails to capture all of this complexity (in ways we shall point out) strengthens our argument.

\subsection{Research Agendas}

Different aspects of music must be approached from a variety of stances: there is no one question about music, but a plurality. Following Love and Brigandt (see below) we call these stances 'research agendas'. Of course, a plurality of agendas does not entail 
a plurality of music concepts, but as we shall see, the complexity of musical research at least makes pluralism attractive.

We take a 'research agenda' to be a perspective from which one might approach the study of music. These perspectives will include a set of investigative concerns. For instance, the scientist interested in psychological models of music will be largely interested in how adult humans process musical information, and the psychological features which underlie musical behaviour. In contrast, the scientist interested in psychological musical development will focus on how these features develop over ontogeny; the changes taking place as children develop. The agendas come apart in terms of the kinds of questions they ask, and the kinds of answers that they want.

There is an issue regarding the commensurability or otherwise of various research agendas. How, indeed, might evolutionary and aesthetic approaches be meshed? For the purposes of this paper, we will put this to one side. Below we give an account of how integration between agendas may occur, but take it that whether some are ultimately incommensurable is a question which can only be answered by doing the science, that is, whether and how specific approaches might be integrated (or not) will be decided by the outcome of research, not a priori.

We characterize the complexity of musical research in a rough and ready way, along two dimensions: level of organization and temporal scale. Fig. 1 loosely sketches this landscape: 


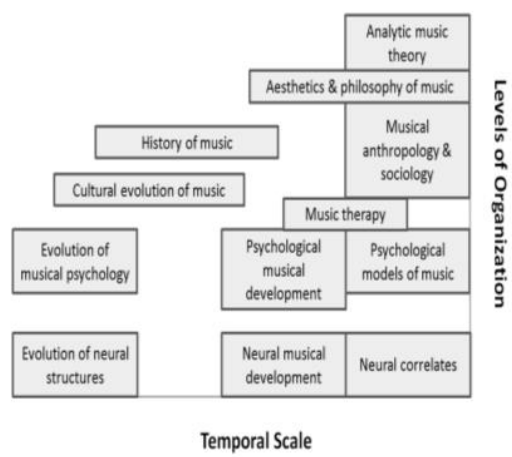

Fig. 1: Research areas along dimensions of abstraction and temporal scale

Fig. 1 is heuristic: it is not an authoritative analysis of the layout of music scholarship. Indeed, there will be many other useful ways of characterising the research space too; we illustrate our conception's utility below. Even so, some caveats are important before we explain the dimensions. Firstly, some domains are probably misplaced: if, as we argue, the biological and cultural aspects of music evolved dynamically, then it might be a mistake to separate the evolution of musical psychology and music's cultural evolution. We return to this thought in $\S 4$. Secondly, for reasons of parsimony, the figure does not clearly distinguish the object of some investigation (for instance, music's evolution) from the method by which some investigation proceeds (for instance, neuroscientific versus psychological). To be sure, we do not endorse conflating objects and methods, as will be clear from our discussion. A more thorough attempt to characterise the voluminous landscape of musical science, beyond the scope of this paper, will by necessity incorporate more dimensions.

Temporal Scale 
Research questions about music can be organised along a temporal scale: some questions are long-range, concerning glacially paced processes in the deep past, while others cover shorter, quicker time-frames. ${ }^{2}$

Ernst Mayr (1961) famously distinguished between ultimate and proximate causes of biological phenomena. Although we do not commit to the distinction (indeed, it is highly problematic, see Ariew, 2003; Beatty, 1994; Calcott, 2013; Laland et al., 2013), it is a useful way of illustrating our point. An 'ultimate cause' explains traits in terms of evolutionary history. We might ask, for instance, whether music is an adaptation, whether musical traits were positively selected for in our evolutionary history. Proximate causes, in contrast, shape an organism over its lifetime-we might wonder from what age a child is able to recognise and remember melodies, for instance. A proximate explanation of birdsong might be that increased light in spring precipitates the release of a hormone in a male songbird's brain (e.g., Moore et al., 2006). The ultimate, evolutionary explanation might be that birdsong indexes the quality of the male bird against its conspecifics, in an effort to attract females with which to breed.

In other words, our temporal scale resembles the phylogeny/ontogeny continuum (Gould 1977). However, the temporal scale is not restricted to questions of evolution and development. As we move from left to right on the temporal axis we shift from research agendas covering the origin of music, its evolution and subsequent historical development, to questions about how musical cognition develops over a lifetime, to theoretical questions about musical structure. At its extreme right end, questions become near-atemporal. Western-style analytic music theory (analysis of music in the Western terms of meter, scales, and so on), for instance, is hardly

2 Note that our use of the term 'scale' is not meant to imply literal measurement. 
temporally bound. ${ }^{3}$ Much of modern cognitive science and psychology is concerned with characterising contemporary human minds, not explaining them in terms of historical forces (for example, see Eerola, 2012 for a computational model of musical emotion perception; Lerud et al., 2014 for a neurodynamic model of auditory response to musical intervals; Neuhaus, 2013 for approaches to musical form processing; Tesoriero and Rickard, 2012 for frameworks for elucidating music-facilitated recall).

How a researcher approaches the study of music, then-that is, the nature of their research agenda-depends in part on temporal scale. Some might target relatively narrow scales, such as the emergence of musical capacities during ontogeny, or anthropological studies of musical expression across human cultures. Others target wider scales like the historian tracing the development of musical styles across centuries, or wider yet, the question of when and why musical capacities appeared in our evolutionary history.

\section{Levels of Organization}

Our other dimension organises research agendas by the 'level of organization' they target. This is a common notion which is nonetheless difficult to specify, philosophically speaking. We can understand a 'level of organization' in terms of either the ontological relationships between targets of investigation, or in terms of how

\footnotetext{
$3 \quad$ Musical features associated with Western music-theoretic concepts, however, are arranged temporally-meter, tonality and so on have specific meanings relative to different eras in music history. A chronology of Western music-theoretic concepts might fall under the broad study of History of music on Fig. 1. Of course, Western music theory is not the only music theory! One of the great weaknesses of much musical research is that it assumes that a Western musical experience is universal (or very nearly) and thus fails to take into account the nature of music/musicality and its social correlates in a variety of non-Western contexts. Some music researchers are acutely aware of this, and keen to point out the problem, and we are deeply sympathetic. Thanks to an anonymous referee for pressing us on this issue.
} 
scientists represent them, their 'level of description'. ${ }^{4}$ Atoms combine to form molecules which themselves form biological entities like proteins, and so on. A psychologist might be interested in positing mental models to explain human musical behaviour and cognition, while a cognitive neuroscientist would posit mechanisms in neural anatomy to ground both those models and (by extension) those same behaviours. The research agendas of cognitive science have typically focused on fairly low levels of organization, such as neural and psychological targets. Proponents of a growing unrest about the limits of this focus urge researchers to take socio-cultural matters into consideration (Bender et al., 2010; Cross, 2012a; Stevens, 2012; Trehub et al., 2015), thus widening focus to include higher levels of organization. Moreover, theoretic musical properties, such as key, pitch, mode and meter (and non-Western analogues), can play an important role in the construction of theories and studies in less abstract sciences.

This picture immediately recalls reductionist models of science, most vividly the 'layer-cake' model (Oppenheim and Putnam, 1958). However, in presenting this picture we do not commit to a reductionist view. First, dividing research questions by level of organization (or description) doesn't commit to there being reductive relationships between those levels (see, for instance Potochnik, 2010; Wimsatt, 1994; Fodor, 1974; Darden and Maull, 1977). Second, as we have stated, our purpose here is to illustrate the wide variety of perspectives from which music can be studied, and this is a helpful way of doing so. Helpful, but deeply flawed. Most strikingly problematic is our placement of highly abstract investigations such as analytic music theory at the highest level of organization-this hardly makes sense! Human social groups do not together form the mathematical structures of musical theory! This would be problematic if our aim was to

\footnotetext{
4 See Craver $(2005,2007)$ for discussions of both different conceptions of 'levels' and integration in
} cognitive neuroscience. 
provide a thorough characterization of the landscape of musical research. However, given that our purpose is to provide a preliminary sketch which motivates pluralism, we think this is adequate for our purposes. As we have said, that our two dimensions fail to capture some aspects of musical research is a feature rather than a bug: it shows that to capture musical research adequately more complexity is required.

Combining the two dimensions provides a set of possible questions, or perspectives, from which one might embark on the project of understanding music; these are different research agendas. Embracing the cluster of research agendas represented by the combination of these two dimensions will drive our pluralism about music concepts.

\subsection{Lines of Evidence and Integration}

Musical science requires a broad range of evidential sources. Here we present some of these, before discussing integration: the relationship between such evidence and research agendas.

Lines of evidence are generated by some technology or technique. A novel line of evidence gains relevance and garners support via background theory which (1) underwrites how the technology in question operates, and (2) links it to some hypothesis.

Lines of evidence utilised by music researchers include-but are by no means limited to-brain scans, behavioural responses (from various stages of development), archaeological finds, cross-cultural ethnography, cross-species comparison, data on happiness/wellbeing, psychiatry, physiology and genetics. Often these lines of evidence are best harnessed by representatives of distinct disciplines-psychology, neuroscience, 
archaeology, anthropology, biology, to name a few. Musical science is a truly interdisciplinary game.

In short, there is a wide range of research agendas guiding us, and a plurality of available empirical resources. Understanding the relationships between these different questions and evidence is important for the field's progress (cf. Fitch, 2015).

Brigandt (2010) and Love (2006) have discussed the relationship between different research agendas and evidence in reference to evolutionary developmental theory and functional morphology, respectively (see also Potochnik, 2010). By their picture, different sources of evidence play different roles depending on which research agenda is salient. For some contexts, a particular agenda, and thus some evidence, carries the explanatory force, while other evidence plays a supporting role. We can determine explanatory force (at least as a rough 'first pass') by considering the pragmatics of explanation. We can ask which agenda provides the relevant answer to a question, and which agendas play supporting roles-that is, provide reasons to believe that answer. Let us explain.

Consider Grahn's (2012) discussion of interval and entrainment models. She asks, which psychological features allow humans to recognise rhythm? The two kinds of models posit different mechanisms to explain human rhythm recognition. An interval model contrasts the beat of a fixed internal clock (or clocks) to an external rhythm, while entrainment models fit an internal oscillator to external stimuli (see Grondin, 2010; McAuley, 2010). As Grahn points out, it is not obvious that models of time intervals are fine-grained enough to handle rhythms (which are sequences of time 
intervals), but it is a useful starting point at any rate. In her paper, Grahn focuses on how neuroscientific data might decide between these hypotheses. ${ }^{5}$

We can understand Grahn's research agenda in terms of 'explanatory force'. Specifically, it seems to us that the psychological perspective-one which posits mental models-is doing the explanatory work. That is, the question 'how do humans recognise rhythm?' is answered by claiming that either interval models, or entrainment models, or perhaps some other psychological model, if instantiated in human psychology, would allow for that capacity. Neuroscience plays a supporting role in this context by helping theorists distinguish between psychological hypotheses. Clearly, for any psychological model to be veridical, it must at least be possible for it to be instantiated in the human brain. If the model cannot be realized, it cannot plausibly capture that aspect of human psychology. This is a relationship between a lower level of organization (about neural correlates) and a slightly higher level (about psychological models for music). The psychological models do the relevant explanatory work, and neuroscientific input provides additional empirical support, individuating competing models and evidentially discriminating hypotheses. This is an example of the kind of integration which our pluralism engenders, that we make explicit in the next section. ${ }^{6}$

\footnotetext{
$5 \quad$ Here, Grahn also discusses the benefits and limitations of employing neuroscientific methods in the study of musical rhythm in general (see also Grahn, 2009).

$6 \quad$ Another example of integration across levels of organization: Temperley (2014) asks which probability model best predicts available data about musical intervals? He distinguishes the Markov model (Rohrmeier et al., 2015; Conklin and Witten, 1995; Pearce and Wiggins, 2004, 2006) from the Gaussian model (von Hippel, 2000; Marr, 1982; Shi et al., 2010); the Markov model defines a musical interval's probability 'by its count in a corpus, conditioned on previous intervals', while the Gaussian model defines it as 'a simple function of the size of the interval to the previous note and the distance to the mean pitch of the melody' (Temperley, 2014, p. 96). These models are tested against three data sets: sequential data from large samples of folksong, chorale, classical, and rock melodies, experimental data from the empirical study of melodic expectation, and distribution data capturing the melodic intervals comprising the Essen Folksong Collection (cf. Schaffrath, 1995). Again, we here see the explanatory force carried by the modelling, and the data from actual
} 
We have suggested that the science of music is doubly complex. First, different research agendas can be conceptualised and organised along two dimensions: level of organization and temporal scale. Second, there is a plurality of evidence-streams which scientists draw on and, as we have just seen, integrate. This situation, we think, is best captured by the notion of a 'research cluster' (Wylie, 1999; Abrahamson, 1987). Institutionally speaking, there is no 'discipline' of musical science. There is, rather, a cluster of disparate research agendas, theories and evidence-generating techniques which, in sum, provide a messy yet promising route to understanding music. Clearly, for such research clusters to advance, attention must be paid to how the various questions and properties mesh. In what follows, we argue that such pluralism runs deep: not only is there a plurality of research agendas targeting music, but a pluralism of music concepts. Moreover, adopting conceptual pluralism about music can aid us in integration.

\section{What is Music?}

As we saw in $\S 2$, musical science involves a cluster of disciplines targeting different agendas and generating different evidence. In our view, there is no unitary, allpurpose definition of music appropriate for these needs. It is worth briefly distinguishing our approach from a more traditional philosophical agenda of specifying individually necessary and jointly sufficient conditions for music.

For example, Andrew Kania proposes three identity conditions:

...music (1) is any event intentionally produced or organized (2) to be heard, and (3) either (a) to have some basic musical feature, such as pitch or rhythm, or (b) to be listened to for such features (Kania, 2011, p. 12).

musical form playing a supporting role; Temperley argues that the Markov model is to be preferred for its lower cross-entropy than that of the Gaussian model (see Temperley, 2014, pp. 90-92). 
(Davies (2012a) and McKeown-Green (2014) propose counterexamples to Kania's analysis.) Kania provides a sophisticated analysis intended to carve the world in a unitary, universal fashion: music simpliciter. In contrast, we think that various musical concepts are best understood as indexed to research agendas. That is, it is our contention that 'music' is not amenable to unitary analysis-at least for the purposes of its scientific investigation. Consider the numerous tensions that arise from different aspects of music, emphasized by different research agendas. Music is sometimes considered a product of intentional action, particularly in anthropological and (some) philosophical settings. Music is sometimes considered an object with particular formal features by, for instance, Western history or analytic theory-but in cross-cultural settings the lack of such features is emphasized. Music can be an expressive function of sociality/culture but can also be considered as a cognitive trait, or in terms of neural mechanisms. Music's various features matter, more or less, for different agendas: that of psychology, music theory, anthropology, and so on. ${ }^{7}$ Even if a unitary account covering all of these uses were available, it is unclear what utility it would serve: the tensions between the various agendas are better resolved, where possible, via piece-meal integration. In short, we are pluralists-non-essentialists-about music.

A pluralist about some category believes there is more than one legitimate and non-equivalent concept pertaining to that category. We can understand 'concepts' as

\footnotetext{
$7 \quad$ For some schematic examples of this tension, note that music that does not meet Kania's 'intentional' requirement might still realize the role of music in some socio-cultural context and thus should be categorised as music by the ethnomusicologist, given their research agenda, but perhaps not by the psychologist, given theirs. Similarly, music that does not meet a (Western) 'basic musical features' requirement might still count as music for the ethnomusicologist and psychologist, but perhaps not for the (Western) music theorist or aesthetician.
} 
providing instructions for dividing up the world: a music concept tells us what is and what isn't 'music', a species concept tells us what it takes for two organisms to be part of the same species. We illustrate this with a crude version of species pluralism. A pluralist about species might hold that the phenetic concept, which classifies species in terms of (usually morphological) similarity, and the biological concept, which classifies them in terms of potential interbreeding, are both legitimate (see Ereshefsky, 1998, 2010; Kitcher, 1984). Paleobiologists interested in broad macro-level patterns might use the phenetic conception, for instance, while evolutionary biologists interested in contemporary lineages may use the biological conception. The justification for pluralism turns on, first, the lack of a unifying concept which meets the needs of various scientists, and second, the equal legitimacy of those scientific concerns.

We take the discussion in $\S 2$, in part, to provide inductive evidence that there is no unifying music concept. Indeed, as we discuss in more detail below, different scientists rely on different (but complementary) 'operationalised' music concepts. As we shall argue, these are non-equivalent and are tailored to particular agendas. Moreover, these agendas (and thus their concepts) seem to us equally legitimate-why should the anthropologist receive short shrift in favour of the neuroscientist, or vice-versa? This is not to say that different music concepts are unrelated or independent. Indeed, pluralism encourages integration.

Although we embrace a plurality of music-concepts, the result is not a chaotic free-for-all. First, the appropriateness and applicability of the concepts are set by the relevant research agenda (cf. Kitcher, 1984 in regards to species pluralism). Second, while some concepts are complementary, others are antagonistic, representing real 
empirical disagreement ${ }^{8}$. In what follows, we describe and illustrate complementary and antagonistic relations between music-concepts. This distinction, in part, drives our pluralism.

Concepts targeting different aspects of music, or music in conjunction with additional elements (e.g., dance or words/poetry), or in different cultures or eras can be complementary. Work from complementary concepts furthers our scientific understanding of music; different definitions can be appropriate for different research agendas, so we need not decide between them as definitions of music simpliciter. Of course, definitions can be better or worse suited to the agenda at hand-and sometimes determining this requires empirical work. So long as the definitions are complementary, we recommend a pluralistic position on music-concepts; we need not privilege any particular one.

An example of complementary definitions can be found in Ian Cross' three-tiered account of music (Cross, 2012a), in turn drawing on the seminal work of ethnomusicologist Alan Merriam $(1963,1964)$. The first is 'concept': music in its contingent, socially constructed guise, indexed to a particular tradition, time, and place. The second, 'behaviour', is the set of human behaviours out of which cultural practice arises. Groups might share musical 'behaviour': for instance they might both spontaneously respond to rhythms with body movements. However, they might differ on musical 'concepts': in one culture music could perform a strictly ritual function, while in another it could be restricted to entertainment. Third is 'sound', the 'acoustical

\footnotetext{
$8 \quad$ Consider the interdisciplinary dissonance which comes to the fore in debates over musical versus linguistic syntax (see e.g. Patel, 2012a, b versus London, 2012; also Slevc et al., 2009 on 'making psycholinguistics musical'), notions of musical 'meaning' (Koelsch, 2011; Cross, 2008; Davies, 1994), and so on. Thanks to an anonymous referee for pressing us on this.
} 
manifestation of musical practices' (Cross, 2012a, p. 672). Here, we may be interested in the various timbres, musical scales, and so on, and how these vary across groups. In short, Cross' distinctions cover different levels of organization. These concepts are complementary: any could be the focus of a research agenda, and such studies need not conflict.

Much work in ethnomusicology and anthropology has elucidated the crosscultural variability both of music itself and how music is conceived (not to mention the diversity of musics within cultures, see Rzeszutek et al., 2012). While in the West music might be characterised in terms of melody, harmony, meter, and so on, as ethnomusicologist Bruno Nettl notes, 'there are societies and musics where these criteria make no sense at all' (Nettl, 2005, p. 18). This shows there is no prima facie reason to think that music can be cashed out in universal terms, that is, with necessary and sufficient identity conditions, or that particular 'salient features' (see Hamilton, 2007) of music can fulfil the needs of various scientists. This all suggests that there is no single, objective sense of music, independent of a research agenda. Furthermore, the Cross-Merriam tripartite account could obviously complement (or be complemented by) definitions cooked up by other theorists (a definition specific to neural-correlates comes to mind).

Another example emerges from the Journal of New Music Research's recent interdisciplinary issue 'espousing different but complementary views on musical rhythm' (Bello et al., 2015, p. 1). Here, cognitive scientific (Schaal et al., 2015), musical performance (Sethares and Toussaint, 2015), ethnomusicological (Holzapfel, 2015), music informational retrieval (Esparza et al., 2015), and signal-processing (Sephus et al., 2015) perspectives on the study of musical rhythm are presented. Let's compare two 
definitions of musical rhythm. Schaal and colleagues, for example, define musical rhythm as the 'temporal organization of the musical material classified by the onset and duration of stimuli and the intervals between the onsets' (Schaal et al., 2015, p. 3). Note that the cognitive scientists' account of 'rhythm' is well-suited to their agenda. If rhythm is understood as the combination of the duration of sound, and the durations of the gaps between sounds, then it may be measured and is a good target for the quantified experimental work of that field. In contrast, Holzapfel distinguishes 'rhythm as a phenomenon inherent in music [from] meter as a mental construct that helps listeners to organize and memorize the temporal structure of music' (Holzapfel, 2015, p. 25). Ethnomusicologists are interested in musical expression across culture, and so dividing 'rhythm' from 'meter' allows them to target the relevant cultural aspect. These distinct disciplines target different concepts, but each identifies an aspect of 'rhythm' for legitimate investigation. The concepts are complementary, and thus also targets of integration.

Of course, pluralists do not hold that every definition of music is acceptable. Sometimes, difference in definition belies empirical disagreement: we call these cases antagonistic. Here, researchers' understanding of what music is-or what some aspect of music is-are at cross purposes. They cannot both be true.

For instance, Honing and Ploeger (2012) distinguish between musicality and music:

We define musicality as a natural, spontaneously developing trait based on and constrained by our cognitive system, and music as a social and cultural construct based on that very musicality. (Honing and Ploeger, 2012, p. 516; emphasis ours.) 
This distinction allows the authors to focus on the evolution of musicality, while black-boxing the complexities of social and cultural aspects (see $§ 4$ for caution). Musicality is said to develop spontaneously, which presumably is meant to separate it from contingent development due to cultural influence. This definition of musicality stands in an antagonistic relationship to others. For instance, Cross (2012a) also distinguishes between music and musicality, but in a strikingly different way:

Cognitive science has dealt with music as though it consists of complexly patterned sounds engaged with through listening for their emotional or hedonic value, and with musicality as though it constitutes an autonomous domain of human thought and behaviour. Musicality seems to be interpreted as arising in two forms, one being the domain of the expert musician whose musicality is acquired partly through native talent and partly through extensive formal training, and who is responsible for producing music, while the other is broadly spread throughout the population, is manifested in the capacity to make sense of, and to be moved by, the complex auditory patterns that constitute music, and is acquired through processes of enculturation. (Cross, 2012a, p. 669; emphasis ours.)

Note that there is no appeal to social and cultural construction in Cross' characterisation of cognitive science's treatment of music-although he does appeal to such factors himself when discussing music in the context of Western musicology (see Cross, 2012a, p. 670)—and conversely there is no appeal to cognitive traits, beyond that of the broad notion of 'talent', in his notion of musicality.

The relationship between these definitions is antagonistic: their differences reflect distinct and conflicting theoretical and empirical commitments. ${ }^{9}$ Cognitive scientists distinguish between music and musicality in order to isolate aspects of the

\footnotetext{
$9 \quad$ Note that Cross does call for a mere terminological revision; he argues that cognitive science should be more sympathetic to accommodating music in non-Western cultures to reach a more comprehensive understanding of human musical faculties. We concur (also, see Stevens, 2012); theorists should be wary of reducing 'music' to 'Western music'.
} 
phenomenon for explanation-but in doing so, claims are made about the causal structures in question. Honing and Ploeger's division between the culturally and biologically determined aspects of music takes it for granted that explanation of these features can be decoupled; Cross' demand that cultural variability be included assumes that this variability matters for the agenda of cognitive science.

How we conceptualise the division between music and musicality matters. Consider whether any natural sounds count as music. For instance, are non-human animal sounds such as birdsong, whale song, gibbon song, coyote calls, cicada chirps, frog croakings and great ape percussive displays, 'music'? As far as there is any consensus in the philosophical literature, for example, it seems to point to the negative (for discussion, see Davies, 2012b). Musicologists, cognitive scientists, and anthropologists, too, have characterised music as an exclusively humanly-produced phenomenon (e.g. Godt, 2005; McDermott, 2008; Trainor, 2015; Rebuschat et al., 2012; Blacking, 1973). Not everyone agrees, of course; the musician David Rothenberg (e.g. 2008) conceives of non-human animal song as music. In any case, if 'music' is operationally defined as a cultural and social construct based on musicality to the extent that it is unique to humans, further research can go on in disciplines such as anthropology, ethnomusicology, psychology and philosophy to explicate the implications of such an understanding, within and across the world's cultures. However, studying non-human animal displays may reveal crucial details relevant to human musicality from a comparative perspective, whether the details are mechanistic, developmental, phylogenetic, or functional (Tinbergen, 1963). Even if music, thusly defined, is distinctly human, it doesn't follow that the traits which underlie music are not shared with other critters. And this means that for some musical research 
agendas-most obviously, those that try to understand musical evolution and development-a comparative perspective could be important. ${ }^{10}$ The concepts researchers work with will reflect this.

In sum, then, we think there are good grounds for pluralism about music concepts. That is to say that there is no single, privileged concept of music, but rather a group of concepts more or less suited to various research agendas. This position is supported both by the plurality of research questions discussed in $\S 2$ and the examples provided in this section. We introduced two ways that music concepts can relate: they can be complementary or antagonistic. Complementary concepts are appropriate for different research agendas, while antagonistic concepts clash, and should be resolved. We suggested that the concepts of 'musicality' in Honing and Ploeger's and in Cross' work are antagonistic.

Here are the three features which we think guide pluralistic research clusters, as we argue music is.

(1) Concepts are relative to research agenda. The applicability of a concept depends upon what question (at what level of organization and temporal scale) the scientists in question are asking. There is no 'one size fits all' music concept.

(2) Concepts are antagonistic or complementary. Some concepts reflect different agendas, and thus may be more-or-less integrated, where others are

\footnotetext{
10 For example, studies have reported interesting findings regarding the cultural evolution of nonhuman animal song (Noad et al., 2000; Payne and Payne, 1993; Payne et al., 1988; Hoeschele et al., 2015; Merchant et al., 2015).
} 
antagonistic: they underlie actual empirical disagreement which ought to be resolved.

(3) Different lines of evidence, and complementary concepts, can often be integrated. Progress in our understanding of music requires that we understand and harness the relationships between these different perspectives.

We think the perspective outlined above has important implications for the scientific investigation of music, and in the next two sections we demonstrate this. First, we look at attempts to explain the evolution of music; second, we turn to music's psychological development. We will, albeit tentatively, put our money where our mouths are: our claims about pluralism are supported by demonstrating how that perspective feeds into empirical debate.

\section{Music and Evolution}

Theories about the nature of systems which have evolved are constrained by their history, by the plausibility of hypotheses about their evolution. Conversely, any evolutionary explanation of some system relies upon facts about the system's presentday properties. In this section we argue that attending to the connections between research agendas suggests that some contemporary approaches to the evolution of music are misconceived. If music has evolved through gene-culture co-evolution-the dynamic interplay between biological and cultural evolution-artificially decoupling the biological and the cultural could be problematic. Here, the relationship between agendas at different temporal scales shows how antagonistic concepts might be resolved. 
There is already an extensive literature on whether music has a proper function in evolutionary terms; that is, whether or not it evolved due to its fitness benefits in past environments (e.g., Cross, 2008, 2007; Davies, 2012b, Dissanayake, 1982, 2008; Fitch, 2005; Huron, 2001, 1999; Miller, 2001, 2000; Mithen, 2005; Morley, 2013; Wallin et al., 2000). In fact, this line of inquiry stretches back at least as far as Darwin's 1871 The Descent of Man. The plausibility of claims about music's evolutionary function turns on which music-concept is employed. As mentioned above, Honing and Ploeger contrast music, the fully-fledged behavioural, social and psychological trait, with musicality, roughly whatever cognitive and neural machinery underlie the culturally-influenced expression of music. Conceived thusly, the suggestion that music is an adaptation is a significantly different thesis than the claim that musicality is.

It is helpful to contrast Honing and Ploeger's approach with that of Pearce and Wiggins (2012), who present a computational model of auditory expectation explicitly constrained by evolution. Instead of considering musical cognitive traits (Honing and Ploeger's focus), they consider music as embedded in, or perhaps emerging from, general cognitive processes. They make two points about such processes: (1) expectation should be reasonably accurate (as like any sensory cognition, getting it right can be the difference between finding food, being eaten, or mating); and (2) the process should be reasonably plastic: 'in complex, changing auditory environments organisms that adapt their expectations to experience are favoured' (Pearce and Wiggins, 2012, p. 627). For Pearce and Wiggins, these considerations suggest that 'innate, generalpurpose learning mechanisms [impose] architectural, not representational, constraints on cognitive development' (Pearce and Wiggins, 2012, p. 627). 
Both parties agree there is some important distinction between music and musicality-after all, the distinction is necessary for investigating whether music is an adaptation. However, they have antagonistic ideas about where to draw the line. Although we have sympathy for Pearce and Wiggins, this foregrounds a deeper issue.

Debate about the proper function of music typically centres on whether some music-concept is best thought of as an adaptation, an exaptation, a spandrel, or a technology (that is, a cultural invention). There is no shortage of adaptationist hypotheses. For instance, Miller $(2001,2000)$ argues that music is an adaptation via sexual selection. Brown (2000) argues that music is a group-level adaptation. Dissanayake (e.g., 1982) argues that the arts (we may include music here) impart 'specialness' and enhance ritual, reinforcing social cohesion. Cross (2007) suggests that music enabled the integration ('bridging the gap') of domain-specific neural substrates (modules), giving rise to domain-general competency; Cross (2012b, 2012c) suggests that music functioned as an interactive situation-management medium in moments of social uncertainty. Dunbar $(1996,1993)$ argues that vocal grooming emerged once hominid group size increased and physical grooming became unsuitable. Several theorists (e.g., Trehub, 2003; Trehub and Trainor, 1998) propose that music's origins are in mother-infant relations: lullaby and play song that produce changes in infant affect and arousal and strengthen mother-infant bonds.

Other theorists are sceptical about music having an evolutionary function. Pinker (1997) argues that music emerged as a by-product of other established cognitive faculties (see also e.g., Barrow, 2005; Panksepp, 2009; Sperber, 1996). Livingstone and 
Thompson (2009) argue that music emerged as a by-product of theory of mind.11 Davies (2012b) argues that even if music is a by-product, it would have eventually taken on adaptive functionality (that is, become an 'exaptation'). Finally, music has been described as a transformative technology, somewhat akin to the discovery and production of fire (Patel, 2010).

As it stands, this debate requires the music/musicality distinction, as we must distinguish between those aspects of music which are plausible targets of evolution by natural selection (say, the cognitive processes which underlie musicality if Pearce and Wiggins are right) from those which are more problematic (say, the specific expression of a musical style). If that distinction separates the biological and cultural aspects of music, their co-evolution could undermine it (Boyd and Richerson, 1985; Feldman and Cavalli-Sforza, 1976; Feldman and Laland, 1996). Traditionally, evolutionary explanation envisions a relatively static environment to which a phenotype is shaped. However, biological and cultural features can create positive feedback. Such dynamic relationships seem likely for music: there is much cultural variation, music has diverse roles in different societies; yet music is ubiquitous and seems to follow a fairly structured developmental sequence (Hannon and Trainor, 2007; Schellenberg and Trainor, 1996; Schellenberg and Trehub, 1996a, b; Stalinski and Schellenberg, 2012; Trainor, 2005; Trainor and Corrigall, 2010). This supports the view that the biological

\footnotetext{
11 To be sure, 'theory of mind' approaches are compatible with other models and hypotheses too, including the co-evolutionary approach that we endorse in the discussion that follows. The uses and implications of theory of mind research is another example of the pluralistic research strategy that we endorse in our paper.
} 
and cultural aspects of music are causally intertwined, evolutionarily speaking: both have shaped each other. ${ }^{12}$

Acknowledging the strong likelihood that music has evolved dynamically (see e.g. Brown et al., 2013) strikes us as foregrounding at least two implications. First, complex co-evolution makes evolutionary explanations couched in terms of adaptation, exaptation, spandrel, and technology much more complex. To an extent, this four-way distinction assumes causal simplicity, a one-way causal arrow, 'environment $\rightarrow$ phenotype', that ignores the implications of a co-evolutionary model. Consequently, one might call into question the usefulness of these distinctions (cf. Killin, 2013). Of course, such co-evolution does not mean that music cannot have an adaptationist explanation. The social/technological invention of cooking, for instance, seems to have spurred evolution in a swathe of our ancestor's physiological traits (tooth size reduction, changes in digestion mechanisms, etc... see Wrangham \& Conklin-Brittain 2003). It is reasonable to say that our reduced tooth size is an adaptation to novel cooking environments. However, note that the environment is dynamic, and that the coupling of cooking and tooth-size is a relatively simple case. Given the sheer complexity of music and musical behaviour, it strikes us that the explanation of music will not be anywhere near so straightforward. The point is not that we cannot give an evolutionary account of music, or that (perhaps) it is ultimately illegitimate to draw distinctions along the lines of 'music/musicality'. The point is that we cannot black-box one or the other in our

\footnotetext{
12 The idea that the biological and cultural aspects of music are correlated and interact is reasonably uncontroversial (cf. Hambrick and Tucker-Drob, 2014), however this has not been adequately reflected in most theories of music evolution (though see Tomlinson, 2015).
} 
explanations. Holistic explanatory models, which combine the 'biological' and 'social' aspects of music and attend to their complex interaction are called for. ${ }^{13}$

Second, theories of cultural evolution and niche construction ought to play a more prominent role in explaining music (following e.g. Merker et al., 2015; Rzeszutek et al., 2012; Tëmkin and Eldredge, 2007; Menary, 2014; Trainor, 2015), and competing theories of music's cultural evolution should be individuated and tested. After all, culture-specific exposure to music seems to influence the development of musical cognitive capacities (Gerry et al., 2010; Hannon and Trehub, 2005a, b; Schellenberg and Trehub, 1999; Soley and Hannon, 2010; Stalinski and Schellenberg, 2012; Trehub, 2003). In our view, these two implications suggest we should shift from traditional evolutionary psychological methods (e.g. Barkow et al., 1992) that have, to some extent, informed prior evolutionary theorising about music (especially that of music's purported status as an adaptation or otherwise; e.g. Honing and Ploeger, 2012).

In this section, we have bought a pluralistic conception to bear on the evolution of music. We contrasted Honing and Ploeger's conception of the divide between 'music' and 'musicality' with Pearce and Wiggins', suggesting that the relationship is antagonistic and in need of empirical investigation. We further argued that coevolutionary models may undermine some distinctions in the context of evolutionary explanation. ${ }^{14}$ If indeed the biological and cultural aspects of music co-evolved in a tight lock-step, then dividing them may be a mistake. Whether our suspicions bear fruit

\footnotetext{
13 We are not necessarily committing to scientific or theory-holism. Rather, we mean a model which incorporates both evidence-streams and complementary definitions from different disciplines. Worries about testing holistic models are not pressing in such cases. In fact, extra streams of evidence can improve our capacity to test such models.

14 We do not deny that such music/musicality distinctions may have important roles in, for instance, anthropological investigation of cross-cultural universals, and so on.
} 
depends on further investigation; our aim has been to illustrate the utility of a pluralistic conception of music.

\section{Nature versus Nurture}

The nature versus nurture debate remains a pressing concern for many music scholars. In this section we illustrate how questions of music's innateness or otherwise are reconceived in light of pluralism. We recommend the construction of integrated, hybrid models which incorporate both learned and innate aspects in explaining the development of musical psychology, and provide a short example of how this may be done.

\subsection{Is Music Innate?}

One key debate in the cognitive science of music (at least since Blacking 1973) concerns the source of musicality's development. The two dominant contemporary hypotheses privilege either innate psychoacoustic principles, or models of exposurebased learning (see Loui, 2012). That is, on the one hand infants come with in-built 'rules' upon which musicality develops, while on the other the infant learns these rules via interaction with other humans and her environment. ${ }^{15}$

Marcus (2012) distinguishes innateness from the so-called 'music instinct', separating two research agendas which, on Marcus' view, are often conflated. First, we can ask whether music is innate, examining cases for an inborn human endowment for

15 One example of this debate targets beat perception. Some (e.g. Winkler et al., 2009) favour an innate model based on the early development of this perception in infants. However, others (e.g. Grahn, 2012) point out that this is too quick: much learning occurs in pre-natal stages. For instance, empirical studies demonstrate that 'infants exposed to particular pieces of music before birth show distinct preferences for those same pieces after birth' (Sloboda, 2005, p. 267; see also Hepper, 1991 and Parncutt, 2009 for more on prenatal and infant musical conditioning). 
music. Second, we can ask whether the suite of cognitive apparatus underlying human musical faculties is domain-specific (cf. Trainor, 2015). These questions are at distinct temporal scales. One is about how musical cognition develops, the other about music's cognitive architecture. Presumably, as Marcus illustrates, the cognitive apparatus enabling chess performance in grandmasters is (at least in part) specific to chess, but it is unlikely there is much support for a 'chess instinct'; chess skills are learned rather than innate. ${ }^{16}$ Perhaps music is also learned yet (at least in part) specific, and Marcus explores this possibility, raising a further series of research questions; in doing so, he nicely illustrates a point which we think should be obvious. The question is not whether music is innate, or domain-specific, but whether music qua-some research agenda is. The tricky part is determining where to draw the lines: discovering which conceptions of music are most amenable to the agenda at hand.

Theorists are divided about music's innateness (Rebuschat et al., 2012); some (e.g., Loui, 2012; Marcus, 2012; Stalinski and Schellenberg, 2012) prefer the explanation that music is more learned than innate, but to different extents. Towards the other end of the continuum, Pearce and Wiggins argue that at least some cognitive aspects of music are not learned, emphasising the 'cognitive process of expectation... in music cognition' (Pearce and Wiggins, 2012, p. 626) and highlighting its potential adaptive benefit. Further still, Honing and Ploeger argue that numerous aspects of music are innate, for example, that beat perception is 'an innate bias, rather than... a result of learning' (Honing and Ploeger, 2012, p. 518).

16 An anonymous referee highlights a disanalogy between the acquisition of chess skills and culturallyappropriate music appreciation: the former is effortful while the latter is a much simpler task. 
What, then, is the answer to the more general question: is music primarily innate or learned? The way forward is to develop hybrid models which elucidate the relationship between learned and innate aspects. A hybrid model integrates several complementary concepts. We illustrate this with a side-step into discussion of comparative research.

\subsection{Entrainment in Vocal Mimics}

Consider two traits: vocal mimicry and entrainment. Vocal learning species, or vocal mimics, are those species capable of vocal mimicry of heard, external sounds: the capacity is seen in various birds, cetaceans (dolphins and whales), pinnipeds (seals and sea lions), and humans (see Patel, 2006). Entrainment is bodily movement/gesture that corresponds with an external rhythmic beat. ${ }^{17}$ Infamous non-human examples include the entrainment to recorded pop music of the sulphur-crested cockatoo Snowball and the African grey parrot Alex (see Fitch, 2009; Schachner, 2013). An extensive YouTube search, exploiting a novel database, provided evidence of entrainment in 33 vocal mimics, and zero non vocal mimics (Schachner, 2013).

No evidence of entrainment has been found in non vocal learning species, and entrainment has never been witnessed in the wild even among vocal mimics (indicating that it has no adaptive fitness). This suggests that entrainment is a by-product of the faculty of vocal mimicry; entrainment does not require any genetic change to the suite of cognitive capacities possessed by the vocal mimic. As our common ancestor with these vocal mimics is truly ancient, this phenomenon is surely a case of convergent evolution. Great apes do not display this trait. Thus cognition of vocal mimicry and

\footnotetext{
17 More precisely, entrainment is the 'coming together' or synchronicity of multiple interacting, though independent, rhythmic oscillators or processes.
} 
entrainment in the animal kingdom is ripe for research and could provide useful analogies for human musical cognition (see Currie, 2013 for a discussion of the role of convergences generally).

So, by identifying and comparing vocal mimicry and entrainment, we can uncover a dependency relationship between them, and gain insight into their development. Briefly, it seems that the apparatus required for vocal mimicry are easily co-opted for entrainment. Presumably, this counts against entrainment being strongly innate. This prediction is testable and research has begun (see Schachner, 2013).

Entrainment research tends to collect behavioural data. To our knowledge, few attempts have been made at collecting neural data related to this topic (though see e.g. Honing et al., 2012; Merchant et al., 2015); this strikes us as one interesting area to develop new research agendas (for review see Hoeschele et al., 2015). For instance, to what extent is the capacity to mimic heard sounds innate? What about the capacity to entrain to a beat/pulse? Are these capacities domain-specific to musicality? If vocal mimicry provided organisms with the cognitive apparatus for entrainment and beat perception, and entrainment is a by-product of vocal learning, then hypotheses may be developed about the innateness of one musical aspect but not another. At the very least, comparative-method theorising foregrounds tentative ways forward (see e.g. Merker, 2012). Indeed, theorists can narrow down potential non-human analogies for musicality (of some relevant kind) since the behaviours in question rely on distinct cognitive apparatus (Fitch, 2005).

By constructing a hybrid model which integrates both the (presumably somewhat innate) capacity for vocal mimicry with the (presumably more learned) capacity for entrainment, a better understanding of both is achieved. Moreover, new 
avenues of investigation open. Obviously, achieving the same for innateness of musical traits in humans in a broader sense would be a very complex task, but we hope the methodological lesson is clear.

\section{Conclusions}

We have tackled both a philosophical task and a scientific one. The philosophical task was to argue that we ought to be pluralists about music-concepts. Support was drawn from our description of the scientific study of music generally, and the two case studies. The scientific task was to show that the philosophical perspective we recommend makes a difference to scientific practice. This was demonstrated by the speculative but (we think) fruitful suggestions made in regards to the case studies.

To understand music in a scientific context, researchers must weave together evolutionary, developmental, behavioural, psychological, cultural and analytic threads, amongst others, into an integrated patchwork. The science of music is indeed an interdisciplinary project. Our methodological recommendation is to divide and then integrate. Difficult questions (e.g. 'is music innate?') are decomposed into simpler targets which can be answered by different lines of evidence, and then synthesised into more holistic and multidisciplinary models. Our discussion has been both schematic and restricted to two specific, though hotly contested, issues. However, many doors have been opened for further enquiry. Which music-concepts are employed, and by theorists of which disciplines? Which music-concepts are complementary and which are antagonistic? How can perspectives from the humanities be integrated with quantified, scientific research? Which evidence-streams bear on which research agendas? There is much more work to be done and the prospect is both challenging and invigorating. 


\section{References}

Abrahamsen, A. A. (1987) Bridging boundaries versus breaking boundariespsycholinguistics in perspective. Synthese 72(3): 355-388.

Ariew, A. (2003) Ernst Mayr's 'ultimate/proximate' distinction reconsidered and reconstructed. Biology \& Philosophy 18(4): 553-565.

Barkow, J., Cosmides, L. \& Tooby, J. (1992) The Adapted Mind: Evolutionary Psychology and the Generation of Culture (New York: Oxford University Press).

Barrow, J. D. (2005) The Artful Universe Expanded (Oxford: Oxford University Press).

Beatty, J. (1994) The proximate/ultimate distinction in the multiple careers of Ernst Mayr. Biology \& Philosophy 9(3): 333-356.

Bello, J. P., Rowe, R., Guedes, C. \& Toussaint, G. (2015) Five perspectives on musical rhythm. Journal of New Music Research 44(1): 1-2.

Bender, A., Hutchins, E. \& Medin, D. (2010) Anthropology in cognitive science. Topics in Cognitive Science 2(3): 374-385.

Blacking, J. (1973) How Musical is Man? (Seattle: University of Washington Press).

Boyd, R. \& Richerson, P. J. (1985) Culture and the Evolutionary Process (Chicago: University of Chicago Press).

Brigandt, I. (2010) Beyond reduction and pluralism: toward an epistemology of explanatory integration in biology. Erkenntnis 73: 295-311.

Brown, S. (2000) Evolutionary models of music: from sexual selection to group selection. In: Perspectives in Ecology 13: Behavior, evolution and culture, F. Tonneau \& N. Thompson (ed.) (New York: Plenum): 231-281.

Brown, S., Savage, P. E., Ko, A. M., Stoneking, M., Ko, Y., Loo, J. \& Trejaut, J. A. (2013) Correlations in the population structure of music, genes and language. Proceedings of the Royal Society B: Biological Sciences 281: 20132072.

Calcott, B. (2013) Why the proximate-ultimate distinction is misleading, and why it matters for understanding the evolution of cooperation. In: Cooperation and Its Evolution, K. Sterelny, R. Joyce, B. Calcott \& B. Fraser (ed.) (Massachusetts: MIT Press): 249-264.

Conklin, D. \& Whitten, I. H. (1995) Multiple viewpoint systems for music prediction. Journal of New Music Research 24: 51-73. 
Craver, C. (2005) Beyond reduction: mechanisms, multifield integration and the unity of neuroscience. Studies in the History and Philosophy of Biological and Biomedical Sciences 36: 373-395.

Craver, C. (2007) Explaining the Brain: Mechanisms and the Mosaic Unity of Neuroscience (Oxford: Oxford University Press)

Cross, I. (2007) Music and cognitive evolution. In: Oxford University Press Handbook of Evolutionary Psychology, L. Barret \& R. I. M. Dunbar (ed.) (Oxford: Oxford University Press): 649-667.

Cross, I. (2008) Musicality and the human capacity for culture. Musicae Scientiae 12 (1 suppl): $147-167$.

Cross, I. (2012a) Cognitive science and the cultural nature of music. Topics in Cognitive Science 4(4): 668-677.

Cross, I. (2012b) Music and biocultural evolution. In: The Cultural Study of Music: a critical introduction, 2nd Edition, M. Clayton, T. Herbert, R. Middleton (ed.) (London: Routlegde): 15-27.

Cross, I. (2012c) Music as a social and cognitive process. In: Language and Music as Cognitive Systems, P. Rebuschat, M. Rohrmeier, J. A. Hawkins, I. Cross (ed.) (Oxford: Oxford University Press): 313-328.

Currie, A. (2013) Convergence as evidence. British Journal for Philosophy of Science 64(4): 763-786.

Darden, L. \& Maull, N. (1977) Interfield theories. Philosophy of Science 44: 43-64.

Davies, S. (1994) Musical Meaning and Expression (Ithaca: Cornell University Press).

Davies, S. (2012a) On defining music. The Monist 95(4): 535-555.

Davies, S. (2012b) The Artful Species: Aesthetics, art \& evolution (Oxford: Oxford University Press).

Dissanayake, E. (1982) Aesthetic experience and human evolution. Journal of Aesthetics and Art Criticism 41(2): 145-155.

Dissanayake, E. (2008) If music is the food of love, what about survival and reproductive success? Musicae Scientiae 12(1 suppl): 169-195.

Dunbar, R. I. M. (1993) Coevolution of neocortical size, group size, and language in humans. Behavioral and Brain Sciences 16(4): 681-735.

Dunbar, R. I. M. (1996) Grooming, Gossip, and the Evolution of Language. (Cambridge: Harvard University Press). 
Eerola, T. (2012) Modeling listeners' emotional response to music. Topics in Cognitive Science 4(4): 607-624.

Ereshefsky, M. (1998) Species pluralism and anti-realism. Philosophy of Science 65(1): 103-120.

Ereshefsky, M. (2010) Species. In: The Stanford Encyclopedia of Philosophy (Spring 2010 Edition), Edward N. Zalta (ed.), URL = <http://plato.stanford.edu/ archives/fall2010/entries/species/>.

Esparza, T. M., Bello, J. P. \& Humphrey, E. J. (2015) From genre classification to rhythmic similarity: computational and musicological insights. Journal of New Music Research 44(1): 39-57.

Feldman, M. W. \& Cavalli-Sforza, L. L. (1976) Cultural and biological evolutionary processes, selection for a trait under complex transmission. Theoretical Population Biology 9(2): 238-259.

Feldman, M. W. \& Laland, K. N. (1996) Gene-culture coevolutionary theory. Trends in Ecology \& Evolution 11: 453-457.

Fitch, W. T. (2005) The evolution of music in comparative perspective. Annals of the New York Academy of Sciences 1060: 29-49.

Fitch, W. T. (2009) Biology of music: another one bites the dust. Current Biology 19(10): 403-404.

Fitch, W. T. (2015) Four principles of bio-musicology. Philosophical Transactions B: Biological Sciences doi 10.1098/rstb.2014.0091.

Fodor, J. A. (1974) Special sciences: or the disunity of science as a working hypothesis. Synthese 28: 97-115.

Gerry, D. W., Faux, A. L. \& Trainor, L. J. (2010) Effects of Kindermusik training on infants' rhythmic enculturation. Developmental Science 13(3): 545-551.

Godt, I. (2005) Music: a practical definition. Musical Times 146: 83-88.

Gould, S. J. (1977) Ontogeny and Phylogeny (Cambridge: Harvard University Press).

Grahn, J. A. (2009) Neuroscientific investigations of musical rhythm: recent advances and future challenges. Contemporary Music Review 28(3): 251-277.

Grahn, J. A. (2012) Neural mechanisms of rhythm perception: current findings and future perspectives. Topics in Cognitive Science 4(4): 585-606. 
Grondin, S. (2010) Timing and time perception: a review of recent behavioral and neuroscience findings and theoretical directions. Attention, Perception \& Psychophysics 72(3): 561-582.

Hambrick, D. Z. \& Tucker-Drob, E. M. (2014) The genetics of music accomplishment: evidence for gene-environment correlation and interaction. Psychonomic Bulletin and Review 22(1): 112-120.

Hamilton, A. (2007) Aesthetics and Music (Michigan: Continuum).

Hannon, E. E. \& Trainor, L. J. (2007) Music acquisition: effects of enculturation and formal training on development. Trends in Cognitive Science 11(11): 466-472.

Hannon, E. E., \& Trehub, S. E. (2005a) Metrical categories in infancy and adulthood. Psychological Science 16(1): 48-55.

Hannon, E. E., \& Trehub, S. E. (2005b) Tuning in to rhythms: infants learn more readily than adults. Proceedings of the National Academy of Sciences 102(35): 12639-12643.

Hepper, P. G. (1991) An examination of fetal learning before and after birth. Irish Journal of Psychology 12(2): 95-107.

Hoeschele, M., Merchant, H., Kikuchi, Y., Hattori, Y. \& ten Cate, C. (2015) Searching for the origins of musicality across species. Philosophical Transactions B: Biological Sciences doi 10.1098/rstb.2014.0094.

Holzapfel, A. (2015) Relation between surface rhythm and rhythmic modes in Turkish makam music. Journal of New Music Research 44(1): 25-38.

Honing, H., Merchant, H., Háden, G. P., Prado, L. \& Bartolo, R. (2012) Rhesus monkeys (macaca mulatta) detect rhythmic groups in music, but not the beat. PLoS ONE 7(12): e51369.

Honing, H. \& Ploeger, A. (2012) Cognition and the evolution of music. Topics in Cognitive Science 4(4): 513-524.

Huron, D. (1999) Ernest Bloch Lectures (Berkeley: University of California Press).

Huron, D. (2001) Is music an evolutionary adaptation? Annals of the New York Academy of Sciences 930: 43-61.

Kania, A. (2011) Definition. In: Routledge Companion to Philosophy and Music, T. Gracyk, A. Kania (ed.) (London: Routledge): 3-13.

Killin, A. (2013) The arts and human nature: evolutionary aesthetics and the evolutionary status of art behaviours. Biology \& Philosophy 28(4): 703-718.

Kitcher, P. (1984) Species. Philosophy of Science 51(2): 308-333. 
Koelsch, S. (2011) Towards a neural basis of processing musical semantics. Physics of Life Reviews 8(2): 89-105.

Laland, K. N., Odling-Smee, J., Hoppitt, W. \& Uller, T. (2013) More on how and why: cause and effect in biology revisited. Biology \& Philosophy 28(5): 719-745.

Lerud, K. D., Almonte, F. V., Kim, J. C. \& Large, E. W. (2014) Mode-locking neurodynamics predict auditory brainstem responses to musical intervals. Hearing Research 308: 4149.

Levinson, J. (1990) Music, art, and metaphysics (Ithaca: Cornell University Press).

Livingstone, S. R. \& Thompson W. F. (2009) The emergence of music from the theory of mind. Musicae Scientiae 13 (2 suppl): 83-115.

London, J. (2012) Schemas, not syntax: a reply to Patel. In: Language and Music as Cognitive Systems, P. Rebuschat, M. Rohrmeier, J. A. Hawkins, I. Cross (ed.) (Oxford: Oxford University Press): 242-247.

Loui, P. (2012) Learning and liking of melody and harmony: further studies in artificial grammar learning. Topics in Cognitive Science 4(4): 554-567.

Love, A. C. (2006) Explaining evolutionary innovations and novelties: criteria of explanatory adequacy and epistemological prerequisites. Philosophy of Science 75(5): 874-886.

Marcus, G. F. (2012) Musicality: instinct or acquired skill? Topics in Cognitive Science 4(4): 498-512.

Marr, D. (1982) Vision (San Francisco: Freeman).

Mayr, E. (1961) Cause and effect in biology. Science 134: 1501-1506.

McAuley, J. D. (2010) Tempo and rhythm. In: Music Perception: Springer Handbook of Auditory Research, M. R. Jones, R. R. Fay \& A. N. Popper (ed.) (New York: Springer): 165199.

McDermott, J. (2008) The evolution of music. Nature 453: 287-288.

McKeown-Green, J. (2014) What is music? Is there a definitive answer? Journal of Aesthetics and Art Criticism 72(4): 393-403.

Menary, R. (2014) The aesthetic niche. British Journal of Aesthetics 54: 471-475.

Merchant, H., Grahn, J., Trainor, L., Rohrmeier, M. \& Fitch, W. T. (2015) Finding the beat: a neural perspective across humans and non-human primates. Philosophical Transactions B: Biological Sciences doi 10.1098/rstb.2014.0093. 
Merker, B. (2012) The vocal learning constellation: imitation, ritual culture, encephalization. In: Music, Language, and Human Evolution, N. Bannan (ed.) (Oxford: Oxford University Press): 215-260.

Merker, B., Morley, I. \& Zuidema, W. (2015) Five fundamental constraints on theories of the origins of music. Philosophical Transactions B: Biological Sciences doi $10.1098 /$ rstb.2014.0095.

Merriam, A. P. (1963) Purposes of ethnomusicology, an anthropological view. Ethnomusicology 7(3): 206-213.

Merriam, A. P. (1964) The Anthropology of Music (Chicago: Northwestern University Press).

Miller, G. F. (2000) Evolution of human music through sexual selection. In: The Origins of Music, N. L. Wallin, B. Merker \& S. Brown (ed.) (Cambridge: MIT Press): 329-360.

Miller, G. F. (2001) Aesthetic fitness: how sexual selection shaped artistic virtuosity as a fitness indicator and aesthetic preference as mate choice criteria. Bulletin of Psychology and the Arts 2(1): 20-25.

Mithen, S. (2005) The Singing Neanderthals (Great Britain: Weidenfeld \& Nicolson)

Moore, I. T., Bentley, G. E., Wotus, C. \& Wingfield, J. C. (2006) Photoperiod-independent changes in immunoreactive brain gonadotropin-releasing hormone (GnRH) in a freeliving, tropical bird. Brain, Behaviour \& Evolution 68(1): 37-44.

Morley, I. (2013) The Prehistory of Music (Oxford: Oxford University Press).

Nettl, B. (2005) The Study of Ethnomusicology: Thirty-one issues and concepts (2nd Edition) (Chicago: University of Illinois Press).

Neuhaus, C. (2013) Processing musical form: behavioural and neurocognitive approaches. Musicae Scientiae 17(1): 109-127.

Noad, M. J., Cato, D. H., Bryden, M. M., Jenner, M. \& Jenner, K. C. S. (2000) Cultural revolution in whale songs. Nature 408: 537.

Oppenheim, P. \& Putnam, H. (1958) The unity of science as a working hypothesis. In Concepts, Theories, and the Mind-Body Problem, G. Maxwell, H. Feigl \& M. Scriven (ed.) (Minneapolis: Minnesota University Press): 3-36.

Panksepp, J. (2009) The emotional antecedents to the evolution of music and language. Musicae Scientiae 13 (2 suppl): 229-259.

Parncutt, R. (2009) Prenatal and infant conditioning, the mother schema, and the origins of music and religion. Musicae Scientiae 13 (2 suppl): 119-150. 
Patel, A. D. (2006) Musical rhythm, linguistic rhythm, and human evolution. Music Perception 24(1): 99-104.

Patel, A. D. (2010) Music, biological evolution, and the brain. In: Emerging Disciplines, M. Bailar, C. Field, C. J. Henry (ed.) (Houston: Rice University Press): 91-144.

Patel, A. D. (2012a) Language, music, and the brain: a resource-sharing framework. In: Language and Music as Cognitive Systems, P. Rebuschat, M. Rohrmeier, J. A. Hawkins, I. Cross (ed.) (Oxford: Oxford University Press): 204-223.

Patel, A. D. (2012b) Advancing the comparative study of linguistic and musical syntactic processing. In: Language and Music as Cognitive Systems, P. Rebuschat, M. Rohrmeier, J. A. Hawkins, I. Cross (ed.) (Oxford: Oxford University Press): 248-253.

Payne, R. B. \& Payne, L. L. (1993) Song copying and cultural transmission in indigo buntings. Animal Behaviour 46(6): 1045-1065.

Payne, R. B., Payne, L. L. \& Doehlert, S. M. (1988) Biological and cultural success of song memes in indigo buntings. Ecology 69(1): 104-117.

Pearce, M. T. \& Wiggins, G. A. (2004) Improved methods for statistical modelling of monophonic music. Journal of New Music Research 33: 367-385.

Pearce, M. T. \& Wiggins, G. A. (2006) Expectation in melody: the influence of context and learning. Music Perception 23: 377-405.

Pearce, M. T. \& Wiggins, G. A. (2012) Auditory expectation: the information dynamics of music perception and cognition. Topics in Cognitive Science 4(4): 625-652.

Pinker, S. (1997) How the Mind Works (London: Allen Lane).

Potochnik, A. (2010) Explanatory independence and epistemic interdependence: a case study of the optimality approach. British Journal for the Philosophy of Science 61: 213233.

Rebuschat, P., Rohrmeier, M., Hawkins, J. A., Cross, I. (ed.) (2012) Language and Music as Cognitive Systems (Oxford: Oxford University Press).

Rohrmeier, M., Zuidema, W., Wiggins, G. A. \& Scharff, C. (2015) Principles of structure building in music, language and animal song. Philosophical Transactions B: Biological Sciences doi 10.1098/rstb.2014.0097.

Rothenberg, D. (2008) Whale music: anatomy of an interspecies duet. Leonardo Music Journal 18: 47-53.

Rzeszutek, T., Savage, P. E. \& Brown, S. (2012) The structure of cross-cultural musical diversity. Proceedings of the Royal Society B. Biological Sciences 279(1733): 1606-1612. 
Schaal, N. K., Banissy, M. J. \& Lange, K. (2015) The rhythm span task: comparing memory capacity for musical rhythms in musicians and non-musicians. Journal of New Music Research 44(1): 3-10.

Schachner, A. (2013) The origins of human and avian auditory-motor entrainment. Nova Acta Leopoldina 111: 243-253.

Schaffrath, H. (1995) The Essen Folksong Collection, D. Huron (ed.) (Stanford: Center for Computer-Assisted Research in the Humanities).

Schellenberg, E. G. \& Trainor, L. J. (1996) Sensory consonance and the perceptual similarity of complex-tone harmonic intervals: tests of adult and infant listeners. Journal of the Acoustical Society of America 100(5): 3321-3328.

Schellenberg, E. G. \& Trehub, S. E. (1996a) Children's discrimination of melodic intervals. Developmental Psychology 32(6): 1039-1050.

Schellenberg, E. G. \& Trehub, S. E. (1996b) Natural intervals in music: a perspective from infant listeners. Psychological Science 7(5): 272-277.

Schellenberg, E. G. \& Trehub, S. E. (1999) Culture-general and culture-specific factors in the discrimination of melodies. Journal of Experimental Child Psychology 74(2): 107-127.

Sephus, N. H., Lanterman, A. D. \& Anderson, D. V. (2015) Modulation spectral features: in pursuit of invariant representations of music with application to unsupervised source identification. Journal of New Music Research 44(1): 58-70.

Sethares, W. A. \& Toussaint, G. (2015) Expressive timbre and timing in rhythmic performance: analysis of Steve Reich's Clapping Music. Journal of New Music Research 44(1): 11-24.

Shi, L., Griffiths, L., Feldman, N. \& Sanborn, A. (2010) Exemplar models as a mechanism for performing Bayesian inference. Psychonomic Bulletin and Review 17: 443-464.

Slevc, L. R., Rosenberg, J. C. \& Patel, A. D. (2009) Making psycholinguistics musical: selfpaced reading time evidence for shared processing of linguistic and musical syntax. Psychonomic Bulletin and Review 16(2): 374-381.

Sloboda, J. A. (2005) Exploring the musical mind (Oxford: Oxford University Press).

Soley, G. \& Hannon, E. E. (2010) Infants prefer the musical meter of their own culture: a cross-cultural comparison. Developmental Psychology 46(1): 286-292.

Sperber, D. (1996) Explaining Culture: a naturalistic approach (Oxford: Blackwell).

Stalinski, S. M. \& Schellenberg, E. G. (2012) Music cognition: a developmental perspective. Topics in Cognitive Science 4(4): 485-497. 
Stevens, C. J. (2012) Music perception and cognition: a review of recent cross-cultural research. Topics in Cognitive Science 4(4): 653-667.

Tëmkin, I. \& Eldgredge, N. (2007) Phylogenetics and material cultural evolution. Current Anthropology 48(1): 146-153.

Temperley, D. (2014) Probabilistic models of melodic interval. Music Perception 32(1): 85-99.

Tesoriero, M. \& Rickard, N. S. (2012) Music-enhanced recall: an effect of mood congruence, emotion arousal or emotion function? Musicae Scientiae 16(3): 340-356.

Tinbergen, N. (1963) On aims and methods of ethology. Zeitschrift für Tierpsychologie 20(4): 410-433.

Tomlinson, G. (2015) A Million Years of Music (New York: Zone).

Trainor, L. J. (2005) Are there critical periods for musical development? Developmental Psychobiology 46(3): 262-278.

Trainor, L. J. (2015) The origins of music in auditory scene analysis and the roles of evolution and culture in musical creation. Philosophical Transactions B: Biological Sciences doi 10.1098/rstb.2014.0089.

Trainor, L. J. \& Corrigall, K. A. (2010) Music acquisition and effects of musical experience. Music Perception 36: 89-127.

Trehub, S. E. (2003) The developmental origins of musicality. Nature Neuroscience 6(7): 669-673.

Trehub, S. E., Becker, J. \& Morley, I. (2015) Cross-cultural perspectives on music and musicality. Philosophical Transactions B: Biological Sciences doi 10.1098/rstb.2014.0096.

Trehub, S. E. \& Trainor, L. J. (1998) Singing to infants: lullabies and play songs. Advances in Infancy Research 12: 43-77.

Von Hippel, P. (2000) Redefining pitch proximity: tessitura and mobility as constraints on melodic intervals. Music Perception 17: 315-327.

Wallin, N. L., Merker, B. \& Brown, S. (ed.) (2000) The Origins of Music (Cambridge: MIT Press).

Wimsatt, W (1994) The ontology of complex systems: levels of organization, perspectives and causal thickets. Canadian Journal of Philosophy (supplementary volume) 20: 207-274. 
Winkler, I., Háden, G. P., Ladinig, O., Sziller, I. \& Honing, H. (2009) Newborn infants detect the beat in music. Proceedings of the National Academy of Sciences of the United States of America 106(7): 1479-1489.

Wrangham, R., \& Conklin-Brittain, N. (2003). Cooking as a biological trait. Comparative Biochemistry and Physiology Part A: Molecular \& Integrative Physiology, 136(1), 35-46.

Wylie, A. (1999) Rethinking unity as a 'working hypothesis' for philosophy: How archaeologists exploit the disunities of science. Perspectives on Science 7(3): 293-317. 